\title{
Diálogos com o Feminino: pelas ondas do rádio mulheres que fazem psicologia para mulheres
}

\section{Dialogues with the Feminine: by radio waves women who do psychology for women}

\section{Diálogos con lo Femenino: por las ondas de radio, mujeres que hacen psicología para mujeres}

\author{
J uliana Ferreira da Silva* \\ Universidade Católica de Brasília - UCB, Brasília, Distrito Federal, Brasil
}

Letícia Dias Albuquerque**

Universidade Católica de Brasília - UCB, Brasília, Distrito Federal, Brasil

Marcela Matias Santos***

Universidade Católica de Brasília - UCB, Brasília, Distrito Federal, Brasil

Milena Almeida da Costa de Oliveira****

Universidade Católica de Brasília - UCB, Brasília, Distrito Federal, Brasil

\begin{abstract}
RESUMO
A pesquisa Diálogos com o Feminino aborda a trajetória de mulheres na psicologia brasileira, buscando evidenciar as especificidades do saber psi que se dedicou às questões do feminino e produziu uma intervenção específica de psicologia feita por mulheres e para mulheres. Esta comunicação apresenta dados da primeira fase da pesquisa, constituindo uma análise de abordagem qualitativa, natureza aplicada, com objetivo exploratório e procedimento de análise documental sobre a contribuição da jornalista e mestre em psicologia social Irede Cardoso para a psicologia articulada ao movimento feminista brasileiro. O estudo parte da experiência do programa de rádio Elas por Elas, compreendendo-o como uma original intervenção sobre a questão da mulher, tanto pelo diálogo que propunha com a psicologia, quanto pela utilização de instrumentos de comunicação via rádio e telefone, assim como pela colocação de questões específicas da mulher de forma coletivizada. Em seguida, são discutidos elementos da biografia de Irede Cardoso, abordando sua trajetória e produção acadêmica. Os resultados demonstram que o saber psi estudado na pesquisa formou esforços para a coletivização da pauta feminista.
\end{abstract}

Palavras-chave: feminismo, história da psicologia, gênero, rádio.

\section{ABSTRACT}

The Dialogues with Feminine research addresses the trajectory of women in Brazilian psychology, seeking to highlight the specificities of psychological knowledge that has been dedicated to feminine issues and has produced a 
specific intervention of psychology by women and for women. This communication presents data from the first phase of the research, constituting an analysis of qualitative approach, applied nature, with an exploratory objective and documental analysis procedure about the contribution of the journalist and master in social psychology I rede Cardoso for the psychology articulated to the Brazilian feminist movement. The study begins with the experience of the radio program "Elas por Elas", understanding it as an original intervention on the issue of women, both for the dialogue it proposed with psychology, and for the use of radio and telephone, as well as by placing specific questions of the woman collectively. Then, elements of the biography of I rede Cardoso are discussed, detailing their trajectory and academic production. The results demonstrate that the psychological knowledge studied in the research has made efforts for the collectivization of the feminist agenda.

Keywords: feminism, history of psychology, gender, radio.

\section{RESUMEN}

La investigación Diálogos con lo Femenino aborda la trayectoria de mujeres en la psicología brasileña, buscando evidenciar las especificidades del saber psi que se dedicó a las cuestiones de lo femenino y produjo una intervención específica de psicología hecha por mujeres y para mujeres. Esta comunicación presenta datos de la primera fase de la investigación, constituyendo un análisis de abordaje cualitativo, de naturaleza aplicada, con objetivo exploratorio y procedimiento de análisis documental sobre la contribución de la periodista y magíster en psicología social I rede Cardoso para la psicología articulada al movimiento feminista brasileño. El estudio se inició con la experiencia del programa de radio Ellas por Ellas, comprendiéndolo como una intervención original sobre la cuestión de la mujer, tanto por el diálogo que proponía con la psicología, como por la utilización de instrumentos de comunicación vía radio y teléfono, así como por la colocación de cuestiones específicas de la mujer de forma colectiva. A continuación, se discuten elementos de la biografía de Irede Cardoso, detallando su trayectoria y producción académica. Los resultados demuestran que el saber psi estudiado en la investigación significó un esfuerzo para la colectivización de la pauta feminista.

Palabras clave: feminismo, historia de la psicología, género, radio.

\section{Sobre mulheres e rádios - ponto de partida: a personagem Samantha White}

No filme e na série de teledramaturgia Cara Gente Branca, Samantha White é uma personagem de ficção jovem estudante de audiovisual que, cansada de sentir-se vítima constante da divisão racial que atinge os alunos de sua universidade - a Winchester University - se junta aos coletivos de alunos negros e cria um programa na rádio comunitária da universidade. Trata-se da personagem principal do filme Dear White People (traduzido no Brasil como Cara Gente Branca), de 2014, produzido nos EUA e dirigido por Justin Simien. O filme deu origem à série com mesmo nome, produzida pela Netflix. Nesse programa, Samantha expõe tensões de seu cotidiano. Aborda episódios de racismo, sexismo e violência sobre os quais tanto a 
comunidade de estudantes quanto a própria instituição educacional fazem vista grossa. A personagem expõe e comenta as ocorrências racistas no campus, discute sobre gênero, colorismo e apropriação cultural e fala sobre a importância do movimento negro e feminista.

Para os propósitos deste trabalho, Cara Gente Branca apresenta uma proposta que gostaremos de tomar como ponto de partida: uma mulher pega um microfone e se dirige a uma comunidade em que está inserida para colocar em pauta suas questões, sofrimentos, insatisfações, indignações, pontos de vista. Essa mulher produz uma pauta de debate, que não se resume a uma leitura de mundo por uma teoria, ou um manifesto político, uma proposta partidária, tampouco a vida de uma celebridade. Ela coletiviza sua experiência no mundo. É sua vivência, seu afeto, suas relações, seu pensamento, seus amores, suas decepções, sua identidade, sua autoestima que estão em evidência. Questões que, coletivizadas, ganham uma esfera pública e política.

Até aqui, a exposição de uma pessoalidade, uma experiência em primeira pessoa - por assim dizer - não é suficiente para entender tudo o que se passa no enredo. Os efeitos da reverberação da experiência coletivizada de Samantha em sua comunidade interessam igualmente. Seu programa de rádio ganha audiência. A comunidade põe-se a ouvi-la frequentemente, sendo um momento de parada das atividades diárias. Além disso, ela passa a receber telefonemas e mensagens que ora são de apoio e suporte, ora de crítica, ódio, queixa e desencorajamento. Samantha usa novamente o rádio para respondê-las, produzindo assim um curioso diálogo sobre as apropriações que os outros fazem de sua história e seu estar no mundo.

Do ponto de vista da psicologia, interessa pensar a operação discursiva de Samantha. Pelo discurso, a personagem coletiviza seus afetos, suas percepções, suas relações e também afirma seu modo de existir. Assim, propomos a questão: como uma operação discursiva como essa poderia relacionar-se à história social da psicologia? Neste trabalho, desenvolvemos a ideia de que a história da emergência da psicologia social crítica na América Latina tem muito a dizer sobre a tal coletivização do viver. O pensamento social crítico da psicologia latino-americana - algo que não se resume a um movimento teórico totalizante ou identitário, mas engloba um conjunto de afirmações de compromissos de uma psicologia que dê conta e responda às inquietações da dimensão social da experiência humana - põe em cena um projeto de psicologia tanto interessado, quanto endereçado à coletividade (Lacerda Jr, 2013). Trata-se de uma psicologia que buscou transpor algo que teria sido em princípio entendido como da ordem de uma intimidade ou de uma individualidade para algo que devesse ser objeto de debate e transformação em ordem coletiva, 
tendo realizado intervenções psicossociais em diversos contextos e variadas dinâmicas sociais (Freitas, 2001).

Uma das questões coletivas de nosso tempo e que motivou a equipe de pesquisa à investigação histórica constitui a colocação da pauta feminista no debate público. Novas reformulações sobre o que seja ser mulher, decorrentes das transformações ocorridas nos últimos cinquenta anos, ancoradas na luta feminista e na ascensão da mulher a espaços tradicionalmente considerados masculinos, produzem transformações no saber e na prática da psicologia brasileira. Partese do entendimento de que uma discussão sobre a subjetividade deva buscar compreender a ação dos sujeitos em suas produções subjetivas cotidianas, interconectadas pelas intensidades dos encontros e transformações entre si e com o mundo (Rolnik \& Guattari, 2007). Assim, partilhamos a aposta de que a compreensão desse processo auxiliará na construção de uma história social da psicologia atenta às especificidades das relações de gênero em nosso país e ao compromisso social dessa ciência com a emancipação da mulher. Desta forma, os dados discutidos fazem parte de uma proposta de pesquisa mais abrangente, ainda em curso, que tem como objetivo geral analisar as histórias de vida e trajetórias profissionais de psicólogas brasileiras que se dedicaram às questões do feminino e produziram uma intervenção específica de psicologia feita por mulheres e para mulheres. No trabalho ora apresentado, propusemos uma discussão sobre a contribuição da jornalista e mestre em psicologia social I rede Cardoso para a psicologia articulada ao movimento feminista brasileiro.

\section{Sobre mulheres e homens - categorias sociais de gênero}

A palavra gênero é marcada pela diferença biológica entre os sexos, porém, na prática social o termo está ligado a uma construção sociocultural do que sejam o feminino e o masculino. Segundo Bourdieu (2010), na sociedade ocidental a diferença biológica entre os gêneros é usada como justificativa para a existência de uma divisão social e do trabalho. Tal distinção foi construída a partir de um discurso androcêntrico - no qual a experiência masculina é tida como a experiência universal - por isso o homem assume a posição de dominador e a mulher de subordinada, ficando evidente uma construção de gênero pautada na oposição entre o masculino e o feminino. A propagação dessa relação de poder homem/mulher é impulsionada pelo discurso machista, que tem como princípio a manutenção desse mecanismo de dominação. O discurso feminista é impulsionado por uma luta contrária aos preceitos machistas, defendendo uma desconstrução do que seja ser mulher e também uma extinção da padronização dos gêneros. O feminismo defende que 
a masculinidade e a feminilidade não podem se limitar a uma série de características, já que são experiências particulares vivenciadas de maneiras diferentes por cada ser. Com isso, as identidades masculina e feminina têm sido debatidas no sentido de uma desconstrução das relações de gênero atualmente estabelecidas. Nesse âmbito, tem sido apontado que transformações sociais, econômicas e culturais podem ser motoras de enfraquecimento do sistema patriarcal, assim como do surgimento de novas configurações familiares, em que a divisão de tarefas passa a ter novos arranjos (Araújo, 2005).

De acordo com Lucila Scavone (2008), o cerne de uma teoria feminista está em discutir como pensamos ou evitamos pensar sobre gênero. Uma sociologia feminista é necessariamente transdisciplinar, visto que utiliza teorias feministas e conversa com as ciências humanas, com a filosofia e com as ciências exatas e biológicas. Os estudos sobre mulheres, como era chamada antes a questão do gênero, começaram na Europa pós-68 e nos Estados Unidos. O campo de investigação sobre as mulheres cresceu a partir disso, expressando a forte ligação entre o movimento social e os estudos feministas. Mas não se deve esquecer que antes disto já havia estudos em sociologia, antropologia, filosofia e literatura - formando um campo de investigação sobre esta questão. Destacam-se como pesquisadoras pioneiras Madeleine Guilbert, Margareth Mead e Simone de Beauvoir. O feminismo obteve suporte na sociedade urbano-industrial moderna, na qual a mulher começa a ganhar mais espaço e começa a adentrar o mercado de trabalho no século XX, assim como passa a ter que conciliar a vida profissional com a familiar. O feminismo é dividido em três grandes fases: a primeira, de caráter universalista ou igualitário, movida pela luta pela igualdade de direitos civis, políticos e sociais; a segunda, de caráter diferencialista ou essencialista, cuja pauta foi marcada pela afirmação das diferenças e identidades; a terceira, desconstrucionista, apoiada nas teorias de sujeitos múltiplos e/ou nômades (Scavone, 2008). As fases descritas representam os séculos XVIII e XIX, a segunda metade e o final do século XX e início de século XXI. Contudo, não é possível marcá-las de modo linear, pois não são fixas e necessitam da situação social, cultural, econômica e política de cada sociedade e momento histórico. Abordagens explicativas são debatidas, de maneira geral, lidando com as polarizações igualdade/diferença, identidades individuais/de grupo, reconhecimento/redistribuição.

No que se refere à produção científica, o maior referencial é masculino, o que leva a considerar a questão do androcentrismo científico. O feminismo da terceira vaga vem afirmando que a ciência é sim o lugar da mulher, mas, além disso, traz propostas emancipatórias para elas. Defende a importância da representatividade do conhecimento científico produzido pelas 
mulheres e busca oportunizar um diálogo sobre a necessidade de se ter uma ciência mais inclusiva e consciente.

\section{Sobre a proposta da pesquisa - métodos, fontes, escolhas e procedimentos}

Este estudo classifica-se como: (i) quanto à abordagem, a pesquisa adota enquadre metodológico qualitativo; (ii) em relação à natureza, enquadra-se em estudo de pesquisa aplicada, uma vez que tenciona gerar conhecimentos para aplicação prática, dirigidos à solução de questões específicas relacionadas ao feminino em psicologia; (iii) quanto a seu objetivo, trata-se de pesquisa exploratória, visto que busca proporcionar maior familiaridade com a experiência de psicólogas na emancipação feminina; (iv) quanto ao procedimento, a pesquisa adotou a metodologia de análise documental. A classificação baseia-se nos critérios Córdova e Silveira (2009). Na análise documental foi pesquisado um periódico feminista brasileiro da década de 1980, denominado Mulherio- acessado na pesquisa pelo portal da Hemeroteca Digital Brasileira - e foi realizado um levantamento da produção acadêmica de Irede Cardoso.

A caracterização do periódico Mulherio precisa partir de um contexto mais geral, tendo-se em perspectiva que a imprensa feminista brasileira tem abrangência nacional e possui caráter contínuo, datando de 1974 até os dias atuais. Além disso, a imprensa feminista pode ser dividida em duas gerações, acompanhando as vagas do movimento feminista (Cardoso, 2004). Os periódicos feministas constituíram um veículo de difusão de ideias, postulação de agendas e diálogo acadêmico em torno da questão de gênero (Freitas, 2014). As transformações políticas cruciais no feminismo brasileiro - que passam a lançar foco de atenção a assuntos como contracepção, sexualidade e violência contra as mulheres - promovem um deslocamento das esferas de debate das questões da mulher. Temas antes relegados ao ambiente doméstico, que não ganhavam expressividade na esfera pública, são, na imprensa feminista, protagonistas do debate numa reflexão sobre a dupla opressão das mulheres brasileiras, a partir dos enfoques de classe e gênero (Freitas, 2014).

O jornal Mulherio é publicado após a Lei da Anistia (1979), período em que a pauta de debate político é marcada pela mobilização pelas Diretas Já, as eleições de 1982 e as discussões acerca da Constituinte. O jornal circulou entre os anos 1980 e 1988, tendo um corpo editorial que nasce de um grupo de pesquisadoras da mulher brasileira da Fundação Ford: Mariza Corrêa, Adélia Borges e Fúlvia Rosemberg. O jornal abordava assuntos que cercam o universo feminino e apresentava matérias que discutem temas polêmicos da 
sociedade, trazendo informações sobre pesquisas e teses feitas sobre a mulher, resenhas e críticas sobre livros, filmes e peças teatrais, charges, dentre outros. Foi apoiado pelas fundações Carlos Chagas e Ford (Tamião, 2009).

A busca do termo psicologia no jornal Mulherio retornou 48 ocorrências. A primeira relata sobre acesso a publicações de diversas áreas do saber - dentre elas a psicologia - na biblioteca de documentação da Fundação Carlos Chagas. A segunda relata sobre um programa de rádio denominado Elas por Elas, que abordava temas relacionados à discriminação feminina e era produzido por Irede Cardoso - uma jornalista e mestre em psicologia social. Considerando que esse programa pudesse constituir interessante material para análise da história social da psicologia sobre a questão do feminino, a equipe de pesquisa decidiu por buscar mais informações sobre ele e também sobre a coordenadora dos debates, Irede Cardoso. Assim, foi feita uma busca na Revista Mulherio sobre as matérias que relatam o nome de Irede Cardoso, tendo sido encontradas 31 ocorrências. Duas delas citam suas publicações com o tema da mulher, sua trajetória acadêmica, a carreira política e profissional. Duas matérias tratam especificamente do Programa de rádio Elas por Elas. Já como vereadora por São Paulo - SP, Irede Cardoso é citada por suas atuações na defesa da mulher e das pautas homossexuais. As demais citações têm caráter informativo: noticiam a participação de Irede Cardoso em palestras, cursos e seminários sobre a questão feminina. Essas matérias foram interpretadas como dados que dão sustentação à presença de Irede Cardoso no debate social sobre a mulher, nos diversos contextos sociais e políticos que a pesquisadora frequentou. A esse respeito vale ressaltar uma matéria na coluna Cartas em que uma leitora afirma ter iniciado a leitura da revista Mulherio após assistir Irede Cardoso numa conferência (Mulherio, Edição 9, 1982).

Foram solicitadas informações sobre o arquivo de áudio do programa ao Museu da Imagem e do Som (MIS) de São Paulo, mas a instituição informou que não dispõe do material solicitado em seu acervo. Assim, foi feita uma busca no portal da Hemeroteca Digital Brasileira com o intuito de encontrar periódicos que trouxessem informações sobre o programa. Foi pesquisada a expressão "Elas por Elas", delimitando a buscaa periódicos de São Paulo entre 1980 e 1981. Tal recorte devese ao tempo de veiculação do programa e ao público, no caso, ouvintes do Estado de São Paulo. A busca retornou quatro ocorrências, três no jornal Mulherio e uma no jornal Ciência e Cultura. A primeira do periódico Mulherio (mai/jun 1981), denominada "Elas por Elas": tribuna livre, relata uma entrevista com Irede Cardoso. A segunda Mulherio (jul/ago 1981) explica que o programa de rádio Elas por Elas passou a ser conduzido por Maria Rita Kehl. A última menção ao programa Mulherio (set/out 1981) 
discorre sobre o término do programa no dia 09 de agosto de 1981. A ocorrência no jornal Ciência e Cultura (fev 1981) faz uso coloquial da expressão elas por elas.

\section{Sobre mulheres e rádios - O Programa Elas por Elas}

Inicialmente, a discussão a partir do uso da comunicação via rádio pela personagem Samantha White visou a colocação de uma ideia seminal: de que a pauta feminista pudesse ser amplificada pelo debate púbico e que esse diálogo pudesse promover transformações nas experiências subjetivas - individuais e coletivas - das mulheres, interessando, portanto, à psicologia. Desta forma, agora propomos pensar sobre essa ideia com base na experiência de I rede Cardoso na condução do programa de rádio Elas por Elas.

O programa de rádio Elas por Elas foi veiculado pela rádio Mulher, no período de abril de 1980 a agosto de 1981, no horário das 11 h00 às 13h00. Era conduzido inicialmente pela mestre em psicologia social Irede Cardoso (abr/1980 a jun/1981) e posteriormente pela psicanalista Maria Rita Kehl (jun a ago/1981). Em seu período inicial, cada edição do programa trazia um tema específico sobre mulheres, que era debatido por Irede Cardoso, pela radialista Meire Gersy e também por convidadas da ocasião. Posteriormente, abria-se um espaço para que as ouvintes trouxessem suas percepções relacionadas ao tema - o que foi denominado tribuna livre. Tal dispositivo político de democratização da fala era tônica dos palanques no movimento pelas Diretas Já. As participantes da tribuna livre do programa eram mulheres de diversas esferas sociais.

Segundo entrevista dada por I rede Cardoso à revista Mulherio, em Maio/J unho de 1981, o programa de rádio possibilitou a criação de um espaço para que as mulheres pudessem falar sobre suas angústias, desejos e interpretações específicas de suas vivências cotidianas. Os temas do protagonismo social e dos direitos da mulher têm papel fundamental na análise de Irede Cardoso. Ela julga que o programa deu nova formulação às falas e pautas das mulheres, tanto como audiência, quanto como partícipes ativas da tribuna livre. Essa entrevista traz elementos centrais para a compreensão do programa e torna-se importante porque explicita - ao nosso ver - um projeto de intervenção que dialoga com o saber psi. 
Figura 1 - Entrevista de Irede Cardoso ao J ornal Mulherio

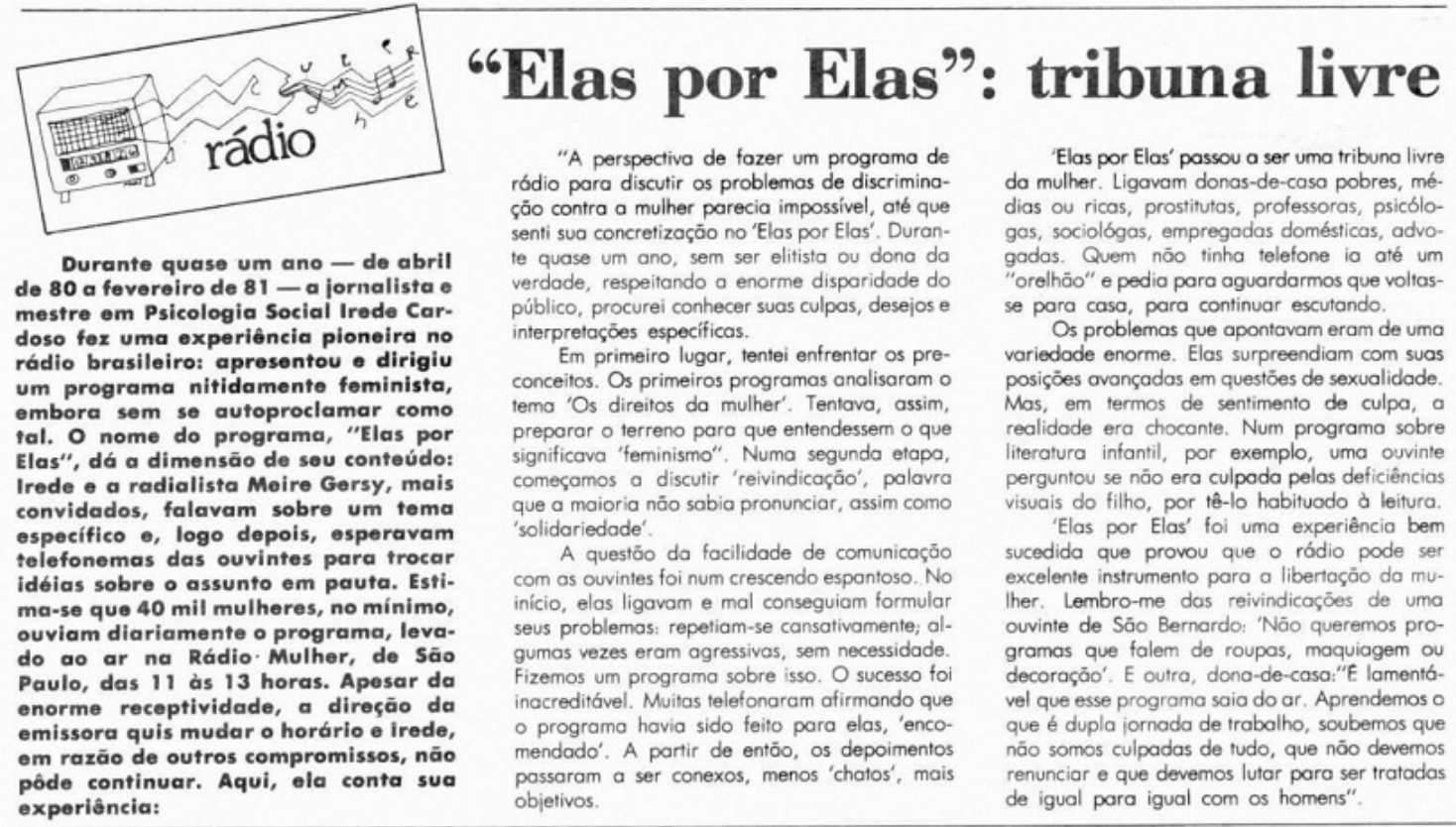

\section{MUT:FRTO}

Fonte: Jornal Mulherio, Edição 00001, Mai/J un de 1981.

Outros tópicos recorrentes na entrevista dizem respeito à culpa e os desejos da mulher, referências conceituais que possivelmente sejam melhor compreendidas tendo em vista a presença forte do saber psicanalítico no contexto de referenciais teóricos do debate sobre a mulher nesse momento histórico. Segundo Tania Santos (1997), a partir de análises que a autora realizou nas seções de aconselhamento nas revistas femininas entre os anos 50 e 80 , podese afirmar que a psicanálise emerge, entre os anos 60 e 70, como 0 principal modelo identificatório adotado pela classe média para a elaboração da sua subjetividade. Esse movimento reposiciona os referenciais de conduta de mulheres, homens e famílias, deslocando a ordem simbólica referencial da moral religiosa para o discurso da ciência médica, tomando a forma de um discurso politizado e crítico que tem como alvo a ordem religiosa cristã. Legitimada por um projeto de saúde mental, que via na adoção de novos valores um imperativo modernizante, a emancipação da mulher toma a forma da cura de uma doença neurótica, na qual a culpa desempenha um papel de destaque. Segundo a autora, nos anos 70, a cura psicanalítica era vista como um meio de liberar o sujeito da culpa inconsciente relacionada ao recalque da fixação nos pais (Santos, 1997).

Não obstante a referência a termos associados ao saber psicanalítico - algo que remete para um modelo de inteligibilidade da subjetividade nos periódicos femininos - a trajetória de Irede Cardoso 
na psicologia esteve associada ao pensamento crítico da psicologia latino-americana. Isso leva a considerar o lugar de fala de Irede Cardoso, como mestre em psicologia social pelo Programa de Estudos Pós-Graduados em Psicologia Social da Pontifícia Universidade Católica de São Paulo (PUC-SP), programa que tem início em 1972 e é o segundo do país. Irede Cardoso é orientada por Silvia Lane pesquisadora emblemática da psicologia social brasileira e fundadora da ABRAPSO. Defendida em 1978, a dissertação de I rede Cardoso insere-se num projeto político para a psicologia social voltado à crítica contundente aos padrões de desigualdades e submissão no país. Alinhada ao pensamento político de esquerda, I rede Cardoso faz a primeira dissertação no Programa acerca da temática do trabalho, afirmando a necessidade de se compreender e modificar as estruturas de desigualdade que permeiam a mulher brasileira, impondo barreiras à ascensão profissional da mulher no sistema capitalista (Souza, 2009). Essa obra é publicada pela Editora Cortez em 1980, sendo utilizada como referência de estudos feministas que relacionam mulher e trabalho no Brasil, pelo enfoque dado ao processo de marginalização da mulher brasileira na educação, trabalho e luta política.

Posteriormente, Irede Cardoso publica mais três livros: Os Tempos Dramáticos da Mulher Brasileira (Cardoso, 1981); O Direito da Mulher na Nova Constituição (Cardoso \& Cardozo, 1986); Cristal da Sabedoria (Cardoso, 1996). A produção acadêmica é dedicada às questões da mulher, apresentando uma reflexão que desconstrói um recorte intimista das relações de gênero, buscando empreender uma discussão abrangente e coletivizada. Assim, é possível destacar importância que Irede Cardoso deu à modulação das pautas de debates sobre os direitos da mulher no programa de rádio, conforme entrevista anteriormente transcrita. Para ela, era importante que o programa funcionasse como um dispositivo de transformação da queixa em reivindicação - algo que aponta para a dimensão política do encontro social.

Na política partidária, I rede Cardoso cumpre dois mandatos como Vereadora de São Paulo - SP pelo Partido dos Trabalhadores (1982 1985; 1986 - 1999). Na primeira eleição, Irede Cardoso obteve mais de 25 mil votos e foi a terceira mulher mais votada. Trabalhou na defesa dos direitos da mulher, ganhando destaque sua atuação na Comissão Especial de Inquérito Sobre a Mulher e discutindo o projeto de lei na Câmara Federal, que deu às donas de casa o direito a aposentadoria. Deixou o Partido dos Trabalhadores em 1990, tendo se filiado ao Partido Verde e posteriormente ao Partido do Movimento Democrático Brasileiro. No jornalismo, continuou a pautar os debates sobre a mulher em âmbito nacional. Assinou a coluna Feminismo no Jornal do Brasil, foi editora do Programa TV Mulher (Rede Globo). Faleceu no ano 2000, por problemas cardíacos. 


\section{Considerações Finais}

A coletivização da pauta feminista e a ampliação dos argumentos de debate sobre a experiência da mulher brasileira interessaram particularmente a esta análise, constituindo seu enfoque principal. Não se pretende, portanto, ter relacionado todas as contribuições e o legado de Irede Cardoso, mas discutir sua original intervenção no diálogo com as mulheres brasileiras, na academia e no debate público, assim como manifestar sua contribuição para o feminismo brasileiro em articulação com a psicologia.

A trajetória de Irede Cardoso articula-se ao desenvolvimento de um campo-tema na psicologia social (Spink, 2003). Integra um movimento de colocação do feminismo tornado psicologicamente relevante e psicologicamente presente nas discussões disciplinares e intervenções sociais da psicologia. A tribuna livre, marca do programa de rádio e dos movimentos sociais, constitui-se como dispositivo de diálogo, propiciando práticas discursivas de confronto e reformulação de sentidos e posições quanto ao gênero. Dessa forma, pela materialidade das conversas e da escrita acadêmica, o feminismo na psicologia social instaura novas pautas, novas vozes, novos argumentos, enfim, novas possibilidades de construção de sentido com a mulher sobre ser mulher.

\section{Referências}

Araújo, M. (2005). Diferença e igualdade nas relações de gênero: revisitando o debate. Psicologia Clínica, 17(2), 41-52.

Bourdieu, P. (2010). A dominação masculina. Rio de Janeiro: Bertrand Brasil. Revista sobre la infancia y la adolescencia, 4, 78-90.

Cardoso, E. (2004). Imprensa feminista brasileira pós-1974. Revista Estudos Feministas, 12(n.e.), 37-55. Recuperado de https:// periodicos.ufsc. br/index. php/ref/article/view/S0104026X2004000300004

Cardoso, I., \& Cardozo, J. E M. (1986). O direito da mulher na nova Constituição. São Paulo: Global.

Cardoso, I. (1980). Mulher e trabalho. São Paulo: Cortez.

Cardoso, I. (1981). Os tempos dramáticos da mulher brasileira. São Paulo: Centro Editorial Latino-Americano.

Cardoso, I. (1996). Cristal da Sabedoria. São Paulo: Musa.

Córdova, F. P., \& Silveira, D. T. (2009). Métodos de pesquisa. UFRGS. Freitas, M. D. F. Q. (2001). Psicologia social comunitária latinoamericana: algumas aproximações e intersecções com a psicologia política. Psicologia Política, 1(2), 54-68. 
Freitas, V. G. (2014). O jornal "Mulherio" e sua agenda feminista: primeiras reflexões à luz da teoria política feminista. história, histórias, 2(4), 149-166.

Lacerda Jr., F. (2013). Capitalismo dependente e a psicologia no Brasil: das alternativas à psicologia crítica. Teoría y Crítica de La Psicología, (3), 216-263.

Rolnik, S., \& Guattari, F. (2007). Micropolítica: cartografias do desejo. Rio de Janeiro: Vozes.

Santos, T. C. (1997). O Movimento Psicanalítico e a Difusão da Psicanálise no Brasil. Tempo Psicanalítico, (29), 171-189.

Scavone, L. (2008). Estudos de gênero: uma sociologia feminista?. Revista Estudos Feministas, 16(1), 173-186. Recuperado de https://periodicos.ufsc. br/index. php/ref/article/view/S0104026X2008000100018

Souza, E. A. (2009) Silvia Lane: uma contribuição aos estudos sobre a Psicologia Social no Brasil. Temas em Psicologia, 17(1), 225245.

Spink, P. K. (2003). Pesquisa de campo em psicologia social: uma perspectiva pós-construcionista. Psicologia \& Sociedade, 15(2), $18-42$.

Tamião, J. S. (2009). Escritas Feministas: os jornais Brasil Mulher, Nós Mulheres e Mulherio (1975-1988) (Dissertação de Mestrado). Pontifícia Universidade Católica de São Paulo, São Paulo, SP.

\author{
Endereço para correspondência \\ J uliana Ferreira da Silva \\ Universidade Católica de Brasília - UCB \\ Programa de Pós-Graduação em Psicologia \\ Campus I, QS 07, Lote 01, EPCT, CEP 71966-700, Taguatinga, Brasília - DF, Brasil \\ Endereço eletrônico: jumeil@hotmail.com \\ Letícia Dias Albuquerque \\ Universidade Católica de Brasília - UCB \\ Programa de Pós-Graduação em Psicologia \\ Campus I, QS 07, Lote 01, EPCT, CEP 71966-700, Taguatinga, Brasília - DF, Brasil \\ Endereço eletrônico: leledias06@gmail.com \\ Marcela Matias Santos \\ Universidade Católica de Brasília - UCB \\ Programa de Pós-Graduação em Psicologia \\ Campus I, QS 07, Lote 01, EPCT, CEP 71966-700, Taguatinga, Brasília - DF, Brasil \\ Endereço eletrônico: marcelamatias83@gmail.com \\ Milena Almeida da Costa de Oliveira \\ Universidade Católica de Brasília - UCB \\ Programa de Pós-Graduação em Psicologia \\ Campus I, QS 07, Lote 01, EPCT, CEP 71966-700, Taguatinga, Brasília - DF, Brasil \\ Endereço eletrônico: myla2305@gmail.com
}


Recebido em: $21 / 12 / 2018$

Reformulado em: 22/02/2019

Aceito em: 23/02/2019

\section{Notas}

* Psicóloga, Doutora em Psicologia pela Universidade Federal do Rio de Janeiro (2016). Mestre em Psicologia pela Universidade Federal do Rio de Janeiro (2008). Especialista em Políticas Públicas de Justiça Criminal e Segurança Pública pela Universidade Federal Fluminense (2005). Graduada em Psicologia pela Universidade Federal Fluminense (2001). Professora do Programa de Pós-Graduação em Psicologia da Universidade Católica de Brasília.

** Graduanda em Psicologia pela Universidade Católica de Brasília.

*** Graduanda em Psicologia pela Universidade Católica de Brasília. Tecnóloga em Gestão de Recursos Humanos pela UNOPAR - Universidade Norte de Paraná (2015). Especialista em Psicopedagogia Clínica e Empresarial pela Universidade Católica de Brasília (2016).

**** Graduanda em Psicologia pela Universidade Católica de Brasília.

Este artigo de revista Estudos e Pesquisas em Psicologia é licenciado sob uma Licença Creative Commons Atribuição-Não Comercial 3.0 Não Adaptada. 